\title{
The Diabetic Diet
}

Dear Sir,

We enjoyed the review article by Dr. Jenkins and co-workers [1] and agree that it is time for diabetologists to start to consider food items not merely on the basis of their biochemical properties (nutrients) but, rather, for their physiological effects (glycaemic response) on metabolism. Bearing this in mind, we find that the recent authoritative dietary recommendations [2-3] have been overtaken, at least in part, by the new body of knowledge which is comprehensively reviewed in Dr. Jenkins' article.

In our opinion simple advice to diabetic patients to increase their carbohydrate consumption, while reducing their lipid intake, makes little sense. However, if interpreted, as in Dr. Jenkins' article, in the sense of an encouragement to substitute calories from butter and dairy products with beans and other legumes, it is appropriate. On the other hand, can an increase in carbohydrate intake, obtained by cutting down the consumption of olive oil and intensifying the use of bread, rice, and potatoes, still be considered a desirable goal for diabetic patients? We substituted $50 \mathrm{~g}$ of olive oil with an isocaloric amount of white bread in the diet ( $2000 \mathrm{Kcal}, 40 \%$ carbohydrate) of six insulin-dependent diabetic patients. This led to a marked deterioration of blood glucose control ( $24 \mathrm{~h}$ monitoring by Biostator): the average daily blood glucose concentration rose from $8.44 \pm 1.28$ to $11.38 \pm 3.50 \mathrm{mmol} / 1$ (mean $\pm \mathrm{SD})(p<0.05)$ and so did the post-prandial blood glucose $(7.99 \pm 3.50$ versus $12.43 \pm 6.05 \mathrm{mmol} / 1, p<0.05)$. Conversely, no substantial modification of serum lipoproteins was found (unpublished data).

Various dietary fats have different effects on serum lipoproteins. Monounsaturated and polyunsaturated lipids are not associated with hyperlipoproteinaemia even if consumed in large quantities [4]. Therefore to prevent atherosclerosis in diabetic patients by dietary means, it is advisable to reduce mainly saturated fats and cholesterol consumption to keep low the serum level of cholesterol and low densitiy lipoproteins which act as powerful risk factors in diabetic patients as in the general population [5].

Moreover, a high consumption of dietary fibre, but not carbohydrates, can improve the blood glucose control in diabetic patients [6] and reduce the serum level of the most atherogenic lipoproteins both in diabetic [6] and non-diabetic [7] individuals.

Therefore, if we want to proceed in the way indicated by Dr. Jenkins' review, we should characterize the diet for diabetic patients not simply by its nutrient composition but rather by the selection of food items known to normalize various metabolic parameters which are deranged in these patients.

The type of diet used in south Italy and in many rural areas of southern Europe not more than two decades ago probably has these characteristics. It is rich legumes, vegetables, fruit, fish, olive oil and spaghetti (which has a favourable glycaemic index!). We and others call this the 'Mediterranean diet' to refer to its geographical and cultural background. Using this diet, we have shown favourable metabolic effects both in diabetic and non-diabetic individuals $[6,7]$.

We believe that the 'Mediterranean diet' will prove to be well accepted in the long-term by diabetic people and, in general, by people who are concerned with health. This might further contribute in the correction of the metabolic abnormalities (by dietary means) which predispose to atherosclerosis.

Yours sincerely

G. Riccardi and A. Rivellese

\section{References}

1. Jenkins DJA, Taylor RH, Wolever TMS (1982) The diabetic diet, dietary carbohydrate and differences in digestibility. Diabetologia 23: $477-484$

2. Committee of the American Diabetes Association on Food and Nutrition (1979) Special report: principles of nutrition and dietary recommendations for individuals with diabetes mellitus. Diabetes Care 2: 520-523

3. Special Report Committee (1981) Guidelines for the nutritional management of diabetes mellitus: a special report from the Canadian Diabetes Association. J Can Dietet Assoc 42: 110-118

4. Report of the WHO Expert Committee (1982) Prevention of coronary heart disease. Technical Report series 678. WHO, Geneva

5. Vaccaro O, Rivellese A, Annuzzi G, Riccardi G, Furnari M, Rubba P, Mancini M (1982) Risk factors for peripheral atherosclerosis in non-insulin-dependent diabetes. Artery 10:341-352

6. Rivellese A, Riccardi G, Giacco A, Pacioni D, Genovese S, Mattioli PL, Mancini M (1980) Effect of dietary fibre on glucose control and serum lipoproteins in diabetic patients. Lancet 2: 447-450

7. Rivellese A, Riccardi G, Giacco A, Postiglione A, Mastranzo P, Mattioli PL (1983) Reduction of risk factors for atherosclerosis in diabetic patients treated with a high fibre diet. Prev Med 12: $128-132$

Dr. G. Riccardi

Clinica Medica II

2nd Medical School

Via S. Pansini 5

I-80131 Naples, Italy

\section{Very Low Density Lipoprotein Metabolism in Non-ketotic Diabetes Mellitus}

\section{Dear Sir,}

Based on their observation that the mean pre-therapy values of very low density lipoprotein (VLDL) triglyceride turnover rates declined following dietary restriction and that this decline was accompanied by a fall in mean VLDL triglyceride levels without significant change in mean fractional catabolic rates, Ginsberg and Grundy [1] concluded that "the primary cause of hypertriglyceridaemia is excessive production of VLDL triglyceride." This conclusion raises important questions about the interpretation of tracer kinetic data, and the article serves to direct attention to the applicability of tracer kinetic studies, as currently employed, in the investigation of pathogenetic mechanisms.

Scrutiny of the pre- and post-therapy patterns of triglyceride kinetics in the individual subjects reported by these authors questions the validity of their assertion. Of the nine patients studied, seven demonstrated some atypical features that are at variance with the authors' interpretation of their findings, as exemplified by patients 4 and 9 , who allegedly "had marked hypertriglyceridaemia without over-production. They thus appeared to have a defect in clearance of VLDL triglyceride."

A more fundamental issue is whether tracer kinetic studies conducted under different steady states [2-6] can identify defects in pathogenetic mechanisms. While there is no disagreement that at a particular steady state and turnover rate, the production and removal rates are equal, nonetheless, at two different steady states, differences in turnover rate are construed as signifying changes in net production (or removal), and accounting for alterations in the triglyceride concentration. A change in turnover rate from one steady state to the next, does not indicate an increase or decrease in net production, as any change in the "synthetic rate" is accompanied by an equal and compensatory alteration in the "removal rate". As a corollary, an alteration in the fractional catabolic rate does not provide an independent estimate of net triglyceride removal or clearance. In tracer studies of the three variables (triglyceride concentration, triglyceride turnover rate and fractional catabolic rate), only two are directly measured (the concentration, and either the fractional catabolic rate or the turnover rate), the third being derived from the other two [7]. Reference to the turnover rate and the fractional catabolic rate as though 
each were independently regulating "production or removal" is erroneous. This issue is highlighted in an Editorial [8] entitled, "Regulation of endogenous plasma triglyceride concentration: can we measure the rate of production or of removal of endogenous plasma triglyceride in man?", in which the author, commenting on an original paper [6] observes, "Contrary to their conclusion that the hypertriglyceridaemia was due to VLDL over-production, my own interpretation of this would be that the cause of the hypertriglyceridaemia had indeed been a reduced fractional removal".

Interpretation of the data of Ginsberg and Grundy without assuming an aetiopathogenetic relationship between the changes in turnover rate and those in plasma concentration depicts a picture of triglyceride kinetics that is totally different from the one drawn by the authors. In this view the turnover rate (which may be normal, hypokinetic, or hyperkinetic) describes the rate of flux into and out of a pool irrespective of its size. Thus, an increased turnover rate (Table 4), may accompany normotriglyceridaemia [1, pre- and post-therapy], hypertriglyceridaemia [5, pre-therapy] and hypotriglyceridaemia [6, post-therapy]; a near-normal turnover, both hypertriglyceridaemia [ 4 , post-therapy] and hypotriglyceridaemia [7, post-therapy]; and a reduced turnover rate may occur with normotriglyceridaemia $[5$, posttherapy] and hypotriglyceridaemia [8, post-therapy]. By the same token, a markedly reduced fractional catabolic rate may accompany normotriglyceridaemia [5, post-therapy?] and hypertriglyceridaemia $[4$, pre- and post-therapy], and a raised fractional catabolic rate, hypotriglyceridaemia $[6$, post-therapy] and normotriglyceridaemia [1, preand post-therapy].

This view of the experimental data, in assuming no causal relationship between the parameters measured, suggests that the assignment of an aetiopathogenetic role to steady state kinetic studies underlies the contradictory interpretation of identical tracer kinetic data. It also raises the question of the physiological significance of variations in turnover rate at different pool sizes. Clearly before the tracer method is applied to the study of pathogenetic mechanisms of hypertriglyceridaemia, these specific issues need to be addressed and resolved.

Yours sincerely,

\section{A.C.Asmal}

\section{References}

1. Ginsberg H, Grundy SM (1982) Very low density lipoprotein metabolism in non-ketotic diabetes mellitus: effects of dietary restriction. Diabetologia 23: 421-425

2. Pietri AO, Dunn FL, Grundy SM, Raskin P (1983) The effect of continuous subcutaneous insulin on very low density lipoprotein triglyceride metabolism in Type 1 diabetes mellitus. Diabetes 32: $75-81$

3. Greenfield M, Kolterman O, Olefsky J, Reaven G (1980) Mechanisms of hypertriglyceridaemia in diabetic patients with fasting hyperglycaemia. Diabetologia 18: 441-444.

4. Kissebah A, Salman A, Evans DJ, Adams PW (1982) Integrated regulation of very low density lipoprotein triglyceride and apolipoprotein-B kinetics in non-insulin-dependent diabetes mellitus. Diabetes 31: 217-225

5. Nikkila EA, Kekki M (1971) Measurement of plasma triglyceride turnover in the study of hypertriglyceridaemia. Scand J Clin Lab Invest 27: 97-104

6. Chait A, Albers JJ, Brunzell JD (1980) Very low density lipoprotein overproduction in genetic forms of hypertriglyceridaemia. Eur $\mathrm{J}$ Clin Invest 10: 17-22

7. Havel RJ, Kane J (1975) Quantification of triglyceride transport in blood plasma: a critical analysis. Fed Proc 34: 2250-2257

8. Carlson LA (1980) Regulation of endogenous plasma triglyceride concentration: can we measure the rate of production or of removal of endogenous plasma triglycerides in man? Eur J Clin Invest 10: 5-7

Dr. A.C.Asmal

Joslin Diabetes Center

1 Joslin Place

Boston, MA 02215

USA

\section{Reply from the Authors}

In his letter, Dr. Asmal appears to be discussing two separate issues and I will therefore address each separately.

Firstly, Dr. Asmal questions our conclusion that "The major cause appears to be an over-production of VLDL triglyceride." The controversy over the aetiology of hypertriglyceridaemia has been active for many years now, but when one surveys the literature, the evidence for increased VLDL production as a major aetiological force is overwhelming. In our study, during the basal state, five of the eight subjects who had studies demonstrated production rates that were outside the range of those measured in our control group, while two other subjects had rates that were at the upper limit of that range. Thus, our conclusion that over-production of VLDL-triglyceride was a major abnormality appears quite reasonable when based on our baseline data alone. Furthermore, although Dr. Asmal attempts to divide our data into several categories based on turnover rates and plasma concentrations of VLDL-triglyceride, we would point out that after energy restriction, five of seven subjects who had VLDL-triglyceride levels within the normal range also had normal production rates. On the other hand, we did not mean to imply that the fractional catabolic rate played no role in the regulation of the plasma VLDL-triglyceride concentration. We would certainly agree that a significant degree of the variability that exists for triglyceride concentration at any level of production results from differences in individual fractional catabolic rates. Indeed, this effect is present in our subjects and was noted in the Discussion.

The second, and more basic issue, centres upon the interpretation of kinetic data derived from injection of a tracer. Dr. Asmal contends that net production or removal cannot be assessed by comparing turnover rates at two different steady states. We would agree that comparison of two different steady states does not provide direct information regarding the events that may have occurred during non-steady state, that is, during the period when the plasma pool was increasing or (as in our study) decreasing. It would be valuable, therefore, to examine the probable non-steady state events that could result in reduced plasma concentrations of VLDL-triglyceride at the new steady state. First, if only the fractional catabolic rate increased during energy restriction, total removal would increase and would be greater than total input (production) which remained unchanged. Plasma levels of VLDL-triglyceride would therefore fall until total removal (plasma concentration $\mathrm{x}$ fractional catabolic rate) once again equalled total production. Since the latter had not changed, the post-energy restriction study (at new steady state) would demonstrate a lower plasma level, an increased fractional catabolic rate, and an unchanged production rate. The conclusion that might be drawn from such data would be that energy restriction reduced plasma VLDL-triglyceride levels by elevating the fractional catabolic rate of this lipid. The second event likely to occur during energy restriction would be an isolated fall in the rate of input (production) of VLDL-triglyceride into plasma. In the face of an unchanged fractional catabolic rate, total removal would be greater than total production and plasma concentration of VLDL-triglyceride would fall until total removal once again came into balance with the lower rate of production. At the new steady state, energy restriction would be associated with reduced plasma levels, reduced rates of production and no change in the fractional catabolic rate of VLDL-triglyceride.

These two simple scenarios would be complicated by physiological relationships between the fractional catabolic rate for VLDL-triglyceride and the plasma concentration of this lipid or by interaction between the plasma concentration and the rate of production of VLDL-triglyceride. However, we do not believe that such complexities would alter our conclusion. For instance, if the fall in VLDL-triglyceride level resulted from a fall in its production rate, the fractional catabolic rate might rise by virtue of the "desaturation' of the lipolytic pathways. While this would produce a larger reduction in the plasma VLDL-triglyceride level than would have occurred if only production had been reduced, the new steady state would still be characterized by a reduced rate of production and reduced plasma concentrations.

In conclusion, although individual variability, suggesting heterogeneity, did exist among our patients, we feel that the following two 
Table 1. Sex, age, percentage ideal body weight, fasting plasma glucose, fasting C-peptide, and coefficients of insulin sensitivity in subjects with or without residual B cell funtion

\begin{tabular}{|c|c|c|c|c|c|c|}
\hline & Sex & $\begin{array}{l}\text { Age } \\
\text { (years) }\end{array}$ & $\begin{array}{l}\text { Ideal } \\
\text { body weight } \\
(\%)\end{array}$ & $\begin{array}{l}\text { Fasting } \\
\text { glucose } \\
(\mathrm{mmol} / \mathrm{l})\end{array}$ & $\begin{array}{l}\text { Fasting } \\
\text { C-peptide } \\
(\mathrm{nmol} / \mathrm{l})\end{array}$ & $\begin{array}{l}\text { Coefficients of } \\
\text { insulin sensitivity }\end{array}$ \\
\hline $\begin{array}{l}\text { With residual } \\
\mathrm{B} \text { cell function }\end{array}$ & $\begin{array}{l}6 \text { females } \\
6 \text { males }\end{array}$ & $33.0 \pm 2.4$ & $98.4 \pm 1.9$ & $7.66 \pm 0.22$ & $0.23 \pm 0.02$ & $2.25 \pm 0.64$ \\
\hline \multirow[t]{2}{*}{$\begin{array}{r}\text { Without residual } \\
\mathrm{B} \text { cell function }\end{array}$} & $\begin{array}{l}6 \text { females } \\
6 \text { males }\end{array}$ & $35.2 \pm 3.5$ & $96.3 \pm 2.2$ & $8.38 \pm 0.31$ & --- & $0.75 \pm 0.11$ \\
\hline & --- & NS & NS & NS & --- & 0.05 \\
\hline
\end{tabular}

Results expressed as mean \pm SEM. Statistical significance of differences calculated by Student's t-test for unpaired data

statements are valid. First, the majority of the patients had hypertriglyceridaemia associated with over-production of VLDL-triglyceride during the baseline period. Second, with energy restriction, VLDLtriglyceride production fell in the majority of the patients while there were quite variable changes in their fractional catabolic rates.

Sincerely,

Dr. H. Ginsberg

Division of Arteriosclerosis and Metabolism

Mount Sinai School of Medicine, New York

and

Dr. S. Grundy

University of Texas Health Science Center

Dallas, Texas

USA

\section{Residual B Cell Function and Insulin Sensitivity in Type 1 (Insulin-Dependent) Diabetes Mellitus}

Sir,

It is now well established that many Type 1 diabetic subjects continue to have some degree of residual B cell function [1]. The metabolic importance of this endogenous insulin production has been emphasized recently in Diabetologia [2]. However, the mechanism(s) whereby persistent B cell secretion may facilitate good metabolic control is poorly understood. Thus, it is of interest that we found a significant positive relationship between basal $B$ cell secretion rate and insulin sensitivity in Type 1 diabetic patients with detectable fasting C-peptide [3].

In the present study, we measured insulin sensitivity in two groups of 12 Type 1 diabetic subjects that differed with respect to residual B cell function. Twelve patients had evidence of residual B cell function, with fasting C-peptide $>0.40 \mathrm{ng} / \mathrm{ml}(0.13 \mathrm{nmol} / 1)$, assessed by the method of Kaneko et al. [4]. The other 12 individuals had undetectable C-peptide, both fasting and in response to IV glucagon. The two groups were similar in sex, age, body weight and plasma glucose concentration. No subject had a serum binding affinity for ${ }^{125}$ I-Insulin $>$ $10 \%[5]$.

The subjects stopped their regular insulin for $12 \mathrm{~h}$ and their longacting insulin for $48 \mathrm{~h}$ before the study. After an overnight fast, at $08.00 \mathrm{~h}$ they received a bolus IV injection of regular insulin (Actrapid MC, Novo, $0.1 \mathrm{IU} / \mathrm{kg}$ body weight). Blood samples were taken from an antecubital vein through an indwelling cannula kept patent by a slow $0.9 \%$ saline infusion before and $5,10,15,20,25,30,35,40$ min after the insulin injection. The glucose disappearance rate with time was calculated from 5 to $25 \mathrm{~min}$ after the insulin injection, and used as an index of insulin sensitivity as described by Alford et al. [6] and BeckNielsen et al. [7].
The diabetic subjects with residual B cell function showed significantly higher coefficients of insulin sensitivity than those without endogenous insulin secretion (Table 1).

The difference in insulin sensitivity may explain, at least in part, the lower insulin requirement and better metabolic control in those Type 1 diabetic subjects with residual B cell activity [2]. Indeed, a continued secretion of insulin into the portal vein and hence directly into the liver may be very important in controlling the hepatic abnormalities of diabetes $[8,9]$. In particular, persistent endogenous insulin production might help to suppress hepatic glucose production and to promote glucose uptake and disposal by the liver, muscle, and adipose tissue.

Yours sincerely,

E. Bonora, C. Coscelli and U. Butturini

\section{References}

1. Hoekstra JBL, Van Rijn HJM, Erkelens DW, Thijssen JHH (1982) C-peptide. Diabetes Care 5: 438-446

2. Madsbad S (1983) Prevalence of residual B cell function and its metabolic consequences in Type 1 (insulin-dependent) diabetes. Diabetologia 24: 141-147

3. Bonora E, Manicardi V, Coscelli C, Butturini U (1982) Relationship between basal B cell activity and insulin sensitivity in healthy, obese, and diabetic man. Diabetologia 23:156 (Abstract)

4. Kaneko T, Oka H, Munemura M, Oda T, Yamashita K, Suzuki S, Yanaihara N, Hashimoto T, Yanaihara C (1974) Radioimmunoassay of human proinsulin C-peptide using synthetic human connecting peptide. Endocrinol Jpn 21: 141-145

5. Christiansen AH (1973) Radioimmunoelectrophoresis in the determination of insulin binding to IgG. Methodological studies. Horm Metab Res 5: 147-154

6. Alford FP, Martin FIR, Pearson MJ (1970) The significance and interpretation of mildly abnormal glucose tolerance. Diabetologia 7 : 173-180

7. Beck-Nielsen H, Pedersen O (1978) Insulin receptors on monocytes of young healthy persons correlated with glucose tolerance and insulin sensitivity. Diabetologia 14: 159-163

8. Madsbad S, Faber OK, Kurtz A, Krarup T, Regeur L, Tronier B, Ørskov H, Binder C, Alberti KGMM (1982) The significance of the portal insulin secretion in insulin-dependent patients with residual beta-cell function: a safeguard against hormonal and metabolic derangement. Clin Endocrinol 16: 605-613

9. DeFronzo RA, Simonson D, Ferrannini E (1982) Hepatic and peripheral insulin resistance: a common feature of Type 2 (non-insulin-dependent) and Type 1 (insulin-dependent) diabetes mellitus. Diabetologia 23: 313-319

Dr. Enzo Bonora

Via Fabio Filzi, 15

I-46100 Mantova

Italy 